\title{
Quality of Preterm Infants' Night Sleep: and Online Community- Based Survey of Maternal Factors and Perceptions of Infants' Nighttime Awakenings and Sleep Problems
}

\author{
Ali Reem ${ }^{1 *}$, Hall Wendy ${ }^{2}$, Warnock Fay ${ }^{2}$, Wong Sabrina ${ }^{2}$, Ratner Pam ${ }^{2}$ \\ ${ }^{1}$ Jordan University of Science and Technology \\ ${ }^{2}$ University of British Columbia \\ *Corresponding author E-mail:raali@just.edu.jo
}

\begin{abstract}
Background: Between one-quarter and one-third of infants aged six months to five years have sleeping problems. Infants' night sleep patterns, in particular problematic night waking with crying, are a common concern for parents. Many factors can influence the development of infants' night sleep patterns and sleep problems, including parental interaction.

Objectives: To examine the associations between premature infants' nighttime awakening, mothers' reports of sleep problem severity, and maternal factors, including mothers' styles of attachment and behaviors used to settle their infants to sleep.

Method: The cross sectional survey study used a web-based questionnaire to collect data from a community-based sample of 105 mothers of singleton premature infants aged 5-6 months (corrected age) across a number of English speaking countries. The main outcome measures were mothers' perceptions of infants' nighttime awakenings (frequency and duration) and presence of infant sleep problems.

Results: Of the $55 \%$ of mothers who reported that their infants had sleep problems, $17 \%$ described the problem as serious. The majority of infants woke 2.1 times per night for an average of 45.7 minutes per night. Mothers' style of attachment and personal history of sleep problems predicted the duration of the infants' nighttime awakening, whereas maternal active physical comforting predicted the frequency of nighttime awakenings.

Conclusions: The findings can guide healthcare providers to screen mothers for an anxious style of attachment, perceptions of infant sleep problems, and use of active physical comforting strategies for bedtime settling when assessing premature infants' sleep problems.
\end{abstract}

Keywords: Maternal Attachment, Nighttime Awakenings, Premature Infant, Settling Strategies, Sleep Problem

\section{Introduction}

Between one-quarter and one-third of infants and young children experience sleep problems (Mindell et al., 2006). The most commonly reported problems are settling difficulties at bedtime and nighttime awakening with signaling (crying) (Goodlin-Jones et al., 2001). Persistent sleep problems during childhood have been associated with attention deficit disorder, impulsivity, aggression, obesity, and poor health-related quality of life (Hiscock et al., 2007; Simola et al., 2012; Taveras et al., 2008; Touchette et al., 2009). Persistent alterations in sleep-wake states may have cumulative and long-term neurodevelopmental effects, especially for preterm infants (Holditch-Davis, 2010). At four months of age, most preterm infants (without neurological complications) are expected to sleep relatively long stretches during the night (approximately six hours) and soothe themselves to sleep following nighttime arousals (Henderson et al., 2011).

Maternal factors including depression, (Lam etal., 2003;), quality of sleep, poor daily functioning (Fiese et al., 2007; Hall et al., 2006 ; Meltzer \& Mindell, 2007), and style of attachment (Benoit et al., 1992) have been linked with children sleep problems. Maternal bedtime behaviors, in particular active physical involvement to settle infants to sleep, e.g. rocking, has been linked to frequent nighttime awakenings (Sadeh et al., 2009; Morrell \& Cortina-
Borja, 2002; Touchette et al., 2005). Because preterm infants represent an understudied population in the community it is important to understand contributions of maternal factors to the quality of premature infants' nighttime sleep.

Preterm infants' responses to everyday stimuli are highly variable, which likely affects maternal interactions (Als, 1982). Differences in the care-giving behaviors of mothers of full-term and mothers of preterm infants have been documented (Feldman \& Eidelman, 2006; Forcada-Guex et al., 2006). Mothers have been more controlling and distant, and less sensitive and synchronized during interactions with their infants (Feldman \& Eidelman, 2006; Forcada-Guex et al., 2006; Muller-Nix et al., 2004). Such behavior has been linked to insecure (anxious) adult attachment styles (Magai et al., 2000).

France and Blampied's (1999) theoretical framework situates infants' nighttime awakening and signaling in the context of anxious mother-infant attachment relationships. They hypothesize that anxiously attached mothers might have intensive or active involvement with their infants at bedtime and in response to their infants' signaled nighttime awakenings. Mothers' overinvolvement behaviors (i.e., active physical comforting) to settle their infants may disrupt infants' sleep regulatory abilities and increase problematic nighttime awakening because infants are unable to develop skills in initiating sleep independently (selfsoothing). 
No published work describes links between mothers' anxious style of attachment, settling behaviors, and perceptions of premature infants' nighttime sleep quality. We aimed to explore the association between mothers' anxious style of attachment, use of active physical comforting strategies to settle their infants, and perceptions of infant sleep problems. Two research questions were explicitly posed:

a) Is maternal bedtime settling behavior, in particular the use of active physical comforting strategies, associated with mothers' reports of sleep problems in their premature infants at five to six months corrected age?

b) Is there an association between mothers' anxious style of attachment and perception of the frequency and duration of premature infants' nighttime awakenings at five to six months corrected age?

\section{Methods}

\subsection{Subjects}

Mothers of premature infants between 5-6 months of age (corrected age) were recruited from the community. The mothers were not receiving therapy for mental health problems. Eligible infants were born between 26 and 36+ 6 weeks gestational age, had birth weights of greater than 1,000 grams, and lived at home. Infants receiving behavioral intervention for sleep problems from healthcare providers or with medical diagnoses of congenital abnormalities or developmental delays were excluded. In total, 105 mothers completed the survey.

\subsection{Procedure}

Ethics approval was obtained from the applicable university, infant development program, and health authority. Recruitment for the online web-based survey occurred through advertising in a local newspaper, on relevant websites, and during health fairs between July 2008 and December 2009.

\subsection{Measures}

\subsubsection{Background information}

The infants' demographic information, including current feeding type, and infant health problems, was collected. Mothers' demographic information, mood, history of sleep problems, and experience with older children with sleep problems were incorporated in the questionnaire.

\subsubsection{The mother's perception of the infant's nighttime awak- ening and infant's sleep problems}

The Brief Infant Sleep Questionnaire (BISQ) (Sadeh, 2004) measured maternal perceptions of infants' night waking and severity of their infants' sleep problems. Test-retest reliability of the BISQ has been reported as .82-.95 and the tool has correlated with other sleep measures (i.e., actigraphic records and daily sleep logs) (Sadeh, 2004). Nighttime awakening was defined as occurring between one hour after the child's bedtime and the start of the next day. Mothers reported the average number of infants' nighttime awakenings (FNW) per night and the total duration of nighttime awakening (DNW) per night during the last typical week. The mothers indicated whether they perceived their infants' sleep as being: "no problem at all," or "a problem (small/ serious)."

\subsubsection{Mothers' bedtime behavior to settle infants}

The Active Physical Comforting (APC) subscale of the Parental Interactive Bedtime Behavior Scale (PIBBS) measured mothers' intense activities to settle their infants (e.g., "rocking," "cuddle," "settle in the parents' bed") (Morrell \& Cortina-Borja, 2002). The APC consists of 6 items, with responses rated on a 5-point scale ranging from $0(0=$ "never") to 4 ( 4 = "very often"). Higher scores indicated more active comforting. Settling in the parents' bed has been significantly correlated with infants' sleeping problems (Morrell \& Cortina-Borja, 2002). In the present study, Cronbach's alpha for the subscale was .75.

\subsubsection{Mothers' anxious attachment style}

The Attachment Style Questionnaire (ASQ), developed by Feeney et al. (1994), measured mothers' styles of attachment. The ASQ scale consists of 40 items, with responses ranging from 1 to 6 , where $1=$ "totally disagree" and $6=$ "totally agree." Thirteen ASQ items that delineated an anxious style of attachment were used for this analysis. The literature provides evidence for the internal consistency of the scale (Alexander et al., 2001 \& Feeney, 2003). In a study of 76 couples' attachment, Feeney (2003) reported that the subscale had an alpha coefficient of .86 , for both men and women. In the present study, the Cronbach's alpha for the subscale was .88 .

\subsubsection{Other study variables}

The exploration of maternal perceptions of length and duration of infants' nighttime awakenings occurred after controlling for family functioning and maternal happiness. The General Functioning (GF) 12-item subscale of the McMaster Family Assessment Device was used to assess family functioning (Epstein et al., 1983). The item response options include: "strongly agree," "agree," "disagree," and "strongly disagree;" six items describe healthy functioning and six items describe unhealthy (pathological) functioning. A higher total score indicates greater family pathology. The internal consistency of the GF has been satisfactory in community samples (Byles et al., 1988 \& Georgiades et al., 2008). For the current study, the Cronbach's alpha was .91.

Maternal overall happiness was assessed using four items from Canada's Health Promotion Survey (Stephens \& Graham, 1993): feelings of being "cheerful and light hearted," "loved and wanted," "downhearted and blue (reverse-scored)," and "lonely (reverse-scored)." The items are scaled from 1 (never) to 4 (always), with higher scores indicating more happiness. The composite scale of these four items has demonstrated acceptable internal consistency (Johnson et al., 2000). In the current study, the Cronbach's alpha was .75.

\subsection{Analysis}

All statistical analyses were conducted using SPSS for Windows 17 and $p$ values (two-sided) of $<0.05$ were considered statistically significant. Scaled variables had acceptable distributions; no multi-collinearity between variables was evident.

Pairs of variables with correlation coefficients $<.20$ were not considered for further analysis. Mann Whitney nonparametric statistics were used to explore the relationships between mothers' use of APC to settle their infants and their perceptions of infants' sleep problems. Hierarchical regression analysis was used to examine relationships between maternal factors, such as mothers' anxious style of attachment and use of active physical comforting strategies, and infants' nighttime awakening. Two separate models were estimated. In the first model, the premature infants' FNW was the outcome variable; infant birth order, family functioning, mothers' use of APC strategies, and maternal style of attachment was predictor variables. In the second regression model, DNW was the outcome variable; family functioning, and maternal history of sleep problems, happiness, use of APC and anxious style of attachment were predictor variables.

\section{Results}

Table 1 provides a summary of the characteristics of the study participants. The majority of infants $(86.7 \%)$ had an appropriate birth weight for their gestational age, $62.9 \%$ were first-born, and 
the mean age of infants was 5.5 months corrected. The majority of the mothers was Caucasian (82\%), well-educated and married.

About half of the mothers (55.2\%) reported that their infants had sleep problems; $17.2 \%$ rated the problem as serious (Table 2 ). The means of the number and duration of nighttime awakenings were 2.1(times per night) and 45.7 (minutes per night), respectively. The number of nighttime awakenings ranged from 0-10 times/night and duration from 0-240 minutes/night. The wide range is due to four infants waking 6-10 times per night, with120240 minutes of nighttime awakening per night. Further analysis of the subgroup of infants with severe nighttime awakenings was not possible due to limited numbers. The Mahalanobis distances analysis showed those data points did not influence the regression model (Huber, 1981).

Table 1: Infant and Maternal Characteristics

\begin{tabular}{|c|c|}
\hline $\begin{array}{l}\text { Demographic and Health Characteristics } \\
\text { Infant Characteristics }\end{array}$ & $\begin{array}{l}\text { Percentage (n) } \\
\mathrm{N}=105\end{array}$ \\
\hline Gender & $61.0(64)$ \\
\hline Type of Birth (\%) & \\
\hline Vaginal & $41.0(43)$ \\
\hline Cesarean & $49.5(52)$ \\
\hline Vacuum/Forceps & $8.6(9)$ \\
\hline Gestational age (weeks) $(\%)^{\mathrm{a}}$ & \\
\hline $26.5-30.6$ & $9.5(10)$ \\
\hline $31.1-34.0$ & $\begin{array}{l}21.9(23) \\
686(72)\end{array}$ \\
\hline $34.1-36.6$ & $68.6(72)$ \\
\hline Multiples (\%) & $96.2(101)$ \\
\hline Singleton & $\begin{array}{l}96.2(101) \\
3.8(4)\end{array}$ \\
\hline Twins & \\
\hline Birth Order (\%) & $62.9(66)$ \\
\hline $\begin{array}{l}\text { First born } \\
\text { Later born }\end{array}$ & $37.1(39)$ \\
\hline Feeding Methods $(\%)^{\mathrm{b}}$ & \\
\hline Exclusive breast feeding & $19.0(20)$ \\
\hline Other & $81.0(84)$ \\
\hline Health problems (\%) & $60.0(63)$ \\
\hline None & $27.6(29)$ \\
\hline Reflux & $4.8(5)$ \\
\hline $\begin{array}{l}\text { Allergy } \\
\text { Transient health problems }{ }^{c}\end{array}$ & $7.6(8)$ \\
\hline $\begin{array}{l}\text { Transient health problems }{ }^{\mathrm{c}} \\
\text { Maternal Characteristics }\end{array}$ & Percentage $(n)$ \\
\hline Ethnicity/Race (\%) & \\
\hline White & $81.9(86)$ \\
\hline Other & $18.1(19)$ \\
\hline Marital Status (\%) & \\
\hline Married/Cohabiting & $93.3(98)$ \\
\hline No Spouse & $6.7(7)$ \\
\hline Education (\%) & \\
\hline Less than high school & $\begin{array}{l}1.0(1) \\
143(15)\end{array}$ \\
\hline High school & $\begin{array}{l}14.3(15) \\
24.8(26)\end{array}$ \\
\hline College & $\begin{array}{l}24.8(26) \\
40.0(42)\end{array}$ \\
\hline Bachelor's degree & $\begin{array}{l}40.0(42) \\
190(20)\end{array}$ \\
\hline Graduate degree & \\
\hline Household Income (CDN\$) (\%) & $6.7(7)$ \\
\hline Under $\$ 25,941$ & $\begin{array}{l}0.7(7) \\
133(14)\end{array}$ \\
\hline$\$ 25,941-\$ 44,196$ & $\begin{array}{l}13.3(14) \\
15.2(16)\end{array}$ \\
\hline$\$ 44,197-\$ 67,211$ & $16.2(17)$ \\
\hline$\$ 67,212-\$ 98,000$ & $40.0(42)$ \\
\hline Over $\$ 98,000$ & $\begin{array}{l}40.0(42) \\
8.6(9)\end{array}$ \\
\hline Declined & \\
\hline Paid work $(\%)$ & $36.2(38)$ \\
\hline Engaged in paid work & $36.2(38)$ \\
\hline Country of Residence (\%) & $40.0(42)$ \\
\hline Canada & $43.8(46)$ \\
\hline USA & $4.8(5)$ \\
\hline Australia & $4.8(5)$ \\
\hline UK & $6.7(7)$ \\
\hline New Zealand & \\
\hline $\begin{array}{l}\text { Maternal History of Sleep Problems (\%) } \\
\text { Sleep Problems }\end{array}$ & $24.8(26)$ \\
\hline Previous experience with infant sleep problems (\%) & $181(19)$ \\
\hline No & 18.1 (19) \\
\hline Yes & $19.0(20)$ \\
\hline Not applicable (first born infant) & $62.1(66)$ \\
\hline Age $($ mean $(\mathrm{SD}))$ & $31.5(5.4)$ \\
\hline
\end{tabular}

A One hundred and five mother- premature infant dyads were in the study; of this sample only two were extremely premature infants (less than 28 weeks of gestation)

B One missing case for feeding method

C Includes ear infection, flu, cough, or stomach upset.
Correlations among predictor variables were in the expected direction. The correlation between mothers' anxious style of attachment and their use of APC during bedtime interactions was very small $(r=.09)$. Infants' birth order was the only confounding variable that met the inclusion criteria for the first regression model with FNW as the criterion. Mothers' histories of sleep problems had a significant positive correlation with infants' duration of nighttime awakening. Mothers reporting a history of sleep problems were more likely to report infant sleep problems compared with mothers with no sleep problem history $(73.1 \%$ versus $49.4 \%$, phi $\left.=.21, \mathrm{p}<.03 ; \chi^{2}=3.54, \mathrm{p}<.05\right)$. Although $19.0 \%$ of the infants were exclusively breastfed, our analysis showed no significant associations between exclusive breastfeeding and outcome variables.

The first research question focused on the relationship between mothers' use of APC and reports of infant sleep problems (sleep problem vs. no sleep problem). Mothers who reported infant sleep problems used more "active physical comforting" strategies (median $=62.5$ ) compared with mothers who had infants with no reported sleep problems $($ median $=45.8)$.

The second research question focused on the association between mothers' anxious style of attachment and the FNW and DNW of premature infants.

In the first regression model, infant birth order, family functioning, APC, and mothers' anxious attachment style accounted for $14.4 \%$ of the variance in the FNW (Table 3). Two variables made a statistically significant contribution when other predictors were held constant: infant's birth order $(\beta=-.25)$ and the mother's use of active physical comforting $(\beta=.24)$. The first-born infants had fewer awakenings, on average. For every standard deviation increase in the mother's use of APC strategies, there was a 0.24 of a standard deviation increase in the FNW.

Table 2: Infants' Sleep-Wake Patterns

\begin{tabular}{|c|c|c|c|c|c|}
\hline Variable & Range & $\begin{array}{l}\text { Mean } \\
\text { (SD) }\end{array}$ & Median & $\begin{array}{l}25^{\text {th }} \text { Percen- } \\
\text { tile }\end{array}$ & $\begin{array}{l}\text { 75th Per- } \\
\text { centile }\end{array}$ \\
\hline $\begin{array}{l}\text { Number of } \\
\text { nighttime awak- } \\
\text { enings }\end{array}$ & $0-10$ & $\begin{array}{l}2.1 \\
(1.6)\end{array}$ & 2.0 & 1.0 & 3.0 \\
\hline $\begin{array}{l}\text { Duration of } \\
\text { nighttime awak- } \\
\text { enings (minutes) }\end{array}$ & $0-240$ & $\begin{array}{l}45.7 \\
(50.8)\end{array}$ & 30.0 & 15.0 & 60.0 \\
\hline $\begin{array}{l}\text { Sleep latency } \\
\text { (minutes) }\end{array}$ & $0-180$ & $\begin{array}{l}33.1 \\
(31.0)\end{array}$ & 20.0 & & \\
\hline $\begin{array}{l}\text { Total daytime } \\
\text { naps (hours) }\end{array}$ & $1.5-8.0$ & $\begin{array}{l}3.5 \\
(1.5)\end{array}$ & 3.0 & & \\
\hline $\begin{array}{l}\text { Total nighttime } \\
\text { sleep (hours) }\end{array}$ & $2-12$ & $\begin{array}{l}9.2 \\
(1.9)\end{array}$ & 10.0 & & \\
\hline $\begin{array}{l}\text { Total sleep in } 24 \\
\text { hours (hours) }\end{array}$ & $\begin{array}{l}5.0- \\
18.5\end{array}$ & $\begin{array}{l}12.7 \\
(2.5)\end{array}$ & 13.0 & & \\
\hline $\begin{array}{l}\text { Consider sleep a } \\
\text { problem }(\mathrm{n}(\%)) \\
\text { Have a problem } \\
\text { Small problem } \\
\text { Serious problem } \\
\text { No problem }\end{array}$ & $\begin{array}{l}58 \\
(55.2) \\
48 \\
(82.7) \\
10 \\
(17.3) \\
47 \\
(44.8)\end{array}$ & & & & \\
\hline
\end{tabular}

In the second regression model, family functioning, and mothers' happiness, history of sleep problems, anxious style of attachment, and use of APC strategies explained $24.2 \%$ of the total variance in the DNW (Table 4). Only maternal history of sleep problems $(\beta=$ .29) and anxious style of attachment $(\beta=.24)$ were significantly associated with DNW. For every standard deviation increase in maternal anxious style of attachment, infants' DNW increased by 0.24 of a standard deviation. Mothers with a history of sleep problems had infants with night waking lasting about one half hour longer, on average, compared with the infants of mothers without sleep problem histories. 
Table 3: Frequency of Nighttime Awakening Regressed on Family Functioning, Birth Order, Mothers' Active Physical Comforting and Anxious Style of Attachment

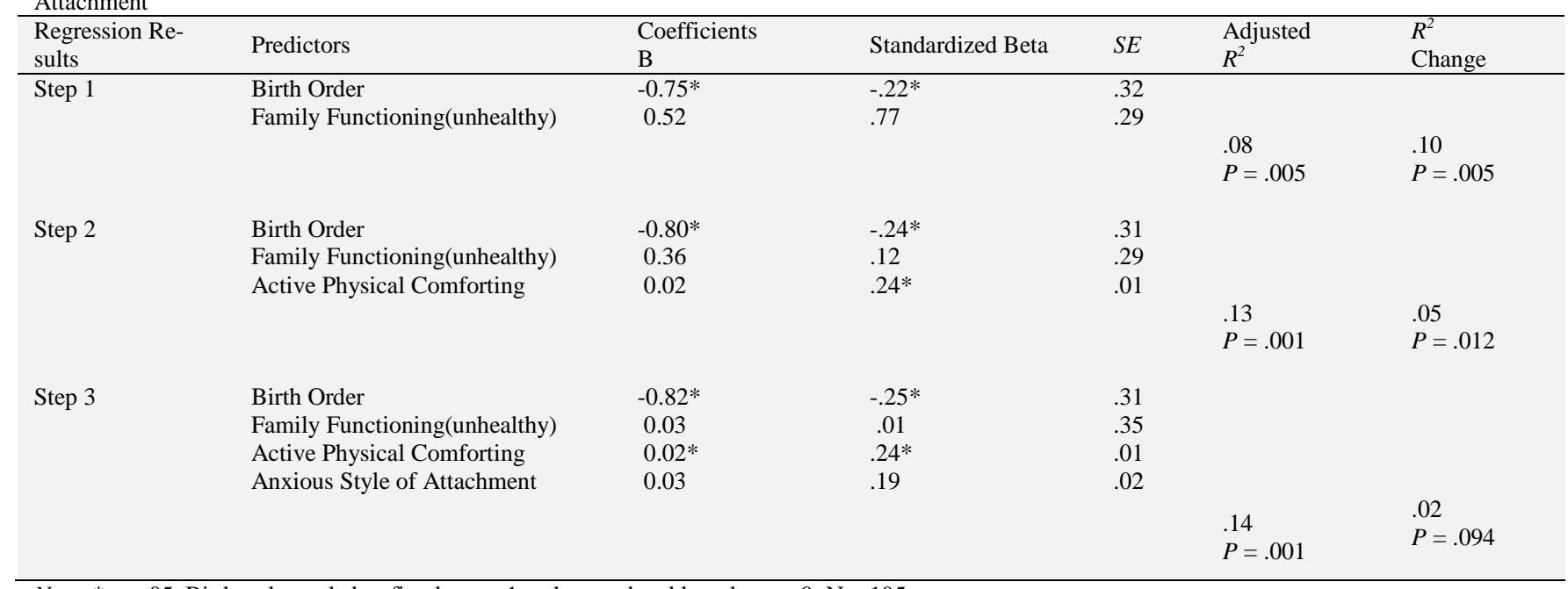

Note. ${ }^{*} p<.05$. Birth order coded as first born $=1$ and second and later born $=0 . \mathrm{N}=105$

Table 4: Duration of Nighttime Awakening Regressed On Family Functioning, Mothers' Happiness, History of Sleep Problems, Use of Active Physical Comforting, And Anxious Style of Attachment

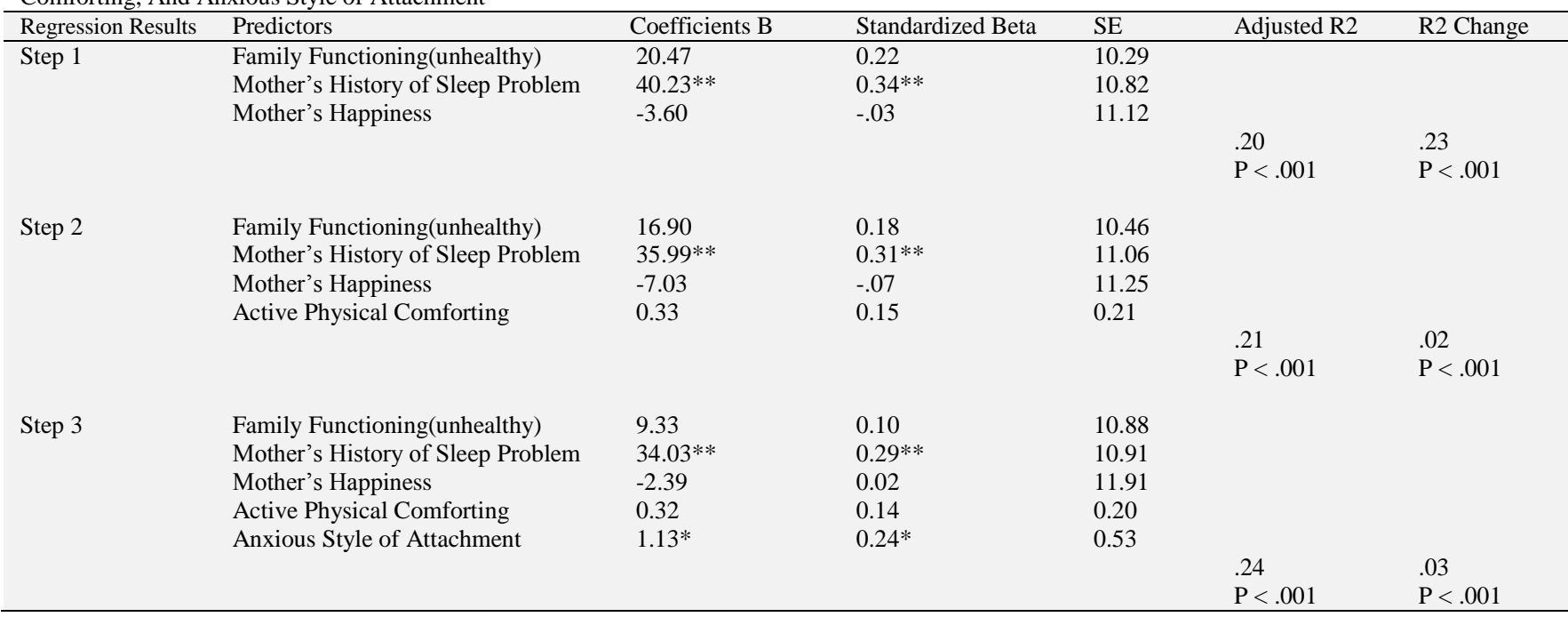

Note. ${ }^{*} \mathrm{p}<.05 ;{ }^{* *} \mathrm{p}<.01 . \mathrm{N}=105$. Mother with sleep problem $=1 ;$ without $=0$

\section{Discussion}

In our study, mothers using more APC strategies were more likely to report that their premature infants had sleep problems. This finding is consistent with other studies demonstrating associations between infants' sleep problems and mothers' intense settling strategies (Morrell \& Steele, 2003; Sadeh et al., 2009; Touchette et al., 2005). The small proportion of variance in FNW, explained by mothers' use of APC strategies, may reflect mothers' inconsistent use of APC. The APC mean was 53.8 (possible range 0100) which implies mothers' settling behaviors were inconsistent The subscale items may have failed to capture all aspects of mothers' intense involvement at bedtime. Although we controlled for important variables, variables other than those we examined may contribute to premature infants' sleep problems.

In this sample, APC was not a predictor of the duration of infants' nighttime awakenings. Including mothers' histories of sleep problems in the model may have reduced the contribution of APC because mothers with sleep difficulties may have kept their infants awake for longer periods. Our result is the first examination of this variable within the context of maternal sleep quality and sleep problems in community-based preterm infants.

Maternal mood previously identified as problematic, was not significantly associated with maternal perceptions of premature in- fants' sleep problems and nighttime awakening. The association between maternal depression and infant night waking is well documented in the literature (Armitage et al., 2009; Hiscock et al., 2008). Our measure may have been inadequate to capture maternal emotional health. Teti and Crosby (2012) reported that videotapes of mothers with depressed mood indicated maternal difficulties with setting sleep limits for infants; the mothers intervened even when their infants were not distressed. Future studies should measure maternal mental health using validated measures, such as the Center for Epidemiologic Studies-Depression Scale (Radloff, 1977), which has been used to measure maternal depressive symptoms when caring for premature infants (Shaha et al., 2013).

Almost half of the mothers in our study practiced "co-sleeping" with their infants either in the same room or in the same bed; however, co-sleeping was not significantly associated with mothers' perceptions of the presence of a sleep problem. Ramos et al. (2007) reported that mothers who chose to "co-sleep" with their infants rated fewer poor infant sleep behaviors than mothers who "co-slept" with their infants in response to their poor sleep behaviors. We did not examine mothers' reasons for co-sleeping. It is possible that mothers of premature infants anticipated co-sleeping as more necessary to settle their infants.

Our findings support theoretically hypothesized associations between mothers' anxious style of attachment and premature infants' nighttime awakenings. In full term populations, infants' insecure attachment has been linked with maternal reports of infant sleep problems (Morrell \& Steele, 2003; Scher, 2001). Benoit et al.'s 
(1992) study of 41 full-term children with diagnosed sleep disorders found that $100 \%$ of mothers with infants in the sleep problem group were insecurely attached compared with $57 \%$ of the mothers in the group without sleep problems.

Mothers' anxious style of attachment explained only $3.3 \%$ of the variance in premature infants' duration of awakening. Our modest finding supports France and Blampied's (1999) theory that mothers' style of attachment is associated with the interaction between mothers and infants' night waking.

The lack of association between a mother's style of attachment and her use of APC settling strategies is not congruent with France and Blampied's (1999) theory that mothers' attachment styles are linked to intense involvement in settling their infants, hindering infants' development of sleep self-initiation skills. The APC subscale may have been inadequate to capture all dimensions of mothers' intense involvement in their infants' settling or the association between maternal use of APC and her style of attachment may have been attenuated by another variable, such as consistency in using comforting strategies. In a study linking infants' sleeping arrangements and mother-infant interaction, consistency in sleep arrangements was associated with more positive mother-infant interaction (Taylor et al., 2008).

We found that infants with pre-existing siblings had more awakenings in a night than first-born infants; however, there was no significant association between birth order and the mothers' report of the presence of infant sleep problems. Other studies have reported that mothers' caretaking interactions have varied in response to full-term infants' birth order (Dunn et al., 1986; Sigman et al., 1981). Mothers with more than one child may be more sensitive to infants' night behavior. The lack of a significant relationship between birth order and the length of night waking may indicate experienced mothers settle their infants more efficiently.

In our study, mothers with histories of sleep problems reported longer infant waking duration and were more likely to identify infant sleep problems. Earlier studies linked poor maternal sleep quality with infant sleep problems (Bayer et al., 2007; Loutzenhiser et al., 2011). We did not collect data on mothers' current sleep problems; however, historical problems may have persisted in this group.

Using a web-based approach increased the recruitment of community-based mothers from several countries; however, the convenience sample limited the generalizability of the study. Most mothers had relatively high socioeconomic status, self-identified as Caucasian and were well educated. Many mothers located the study through a website devoted to helping parents handle infant sleep problems, which may have introduced sampling bias. The cross-sectional study design prevents any claims about cause and effect. Reliance on a subjective sleep measure (maternal selfreport) to determine presence of infants' sleep problems is a limitation.

The study findings have the potential to increase healthcare providers' awareness of active physical comforting strategies, mothers' sleep quality and mothers' attachment style when assessing and treating sleep problems in premature infants. Detailed assessments can help nurses and other healthcare practitioners identify infants at risk of developing sleep problems.

\section{Conclusion}

To our knowledge this is the first study to investigate the relationship between mothers' anxious attachment style and premature infant sleep problems. Mothers' anxious style of attachment was associated with longer duration of infants' nighttime awakenings. The study findings add information about the association between mothers' use of active physical comforting strategies and maternal identification of sleep problems in premature infants. Our findings shift the focus to maternal factors, such as sleep quality and style of attachment, when assessing premature infant sleep problems.

\section{Acknowledgements}

This research comprised the dissertation of the first author which was submitted to University of British Columbia in partial fulfillment of the requirements for the Ph.D. degree. This study was partially funded by graduate research studentship award to the first author from school of nursing, University of British Columbia and the Xi Eta Chapter, Sigma Theta Tau International. We are thankful to the mothers for agreeing to participate in this study and we offer our regards to the Infant Development Program staff, the Sleep Network, the hosts of the Babyvibe website, the Fussybaby website managers and Vancouver Coastal Health for their support during data collection. A special acknowledgement goes to $\mathrm{Dr}$. Michael Whitfield, MD, FRCPC for his supervision and support.

\section{References}

[1] Alexander, R. Feeney, J., Hohaus, L., \& Noller, P. (2001). Attachment style and coping resources as predictors of coping strategies in the transition to parenthood. Personal Relationships, 8, 137- 152.

[2] Als, H. (1982). Toward a synactive theory of development: Promise for the assessment and support of infant individuality. Infant Mental Health Journal, 3, 229-243.

[3] Armitage, R., Flynn, H., Hoffmann, R., Vazquez, D., Lopez, J., \& Marcus, S. (2009). Early developmental changes in sleep in infants: The impact of maternal depression. Sleep, 32, 693-696.

[4] Bayer, J.K., Hiscock, H., Hampton, A., \& Wake, M. (2007). Sleep problems in young infants and maternal mental and physical health. Journal of Paediatric and Child Health, 43, 66-73.

[5] Benoit, D., Zeanah, C. H., Boucher, C., \& Minde, K. K. (1992). Sleep disorders in early childhood: Association with insecure maternal attachment. Journal of the American Academy of Child and Adolescent Psychiatry, 31, 86-93.

[6] Byles, J., Byrne, C., Boyle, M., \& Offord, D. (1988). Ontario Child Health Study: Reliability and validity of the general functioning subscale of the McMaster Family Assessment Device. Family Process, 27 97-104

[7] Dunn, J. F., Plomin, R., \& Daniels, D. (1986). Consistency and change in mothers' behavior toward young siblings. Child Development, 57, 348-356

[8] Epstein, N. B., Baldwin, L. M., \& Bishop, D. S. (1983). The McMaster Family Assessment Device. Journal of Marital and Family Therapy, 9, 171-180

[9] Feeney, J. A. (2003). Adult attachment, involvement in infant care, and adjustment to new parenthood. Journal of Systemic Therapies, 22, 16-30.

[10]Feeney, J. A., Noller, P., \& Hanrahan, M. (1994). Assessing adult attachment. In M. B. Sperling \& W. H. Berman (Eds.), Attachment in adults: Clinical and developmental perspectives (pp. 128-152). New York: Guilford Press.

[11]Feldman, R., \& Eidelman, A. I. (2006). Neonatal state organization, neuromaturation, mother-infant interaction, and cognitive development in small-for-gestational-age premature infants. Pediatrics, 118 , e869-e878. DOI: 10.1542/peds.2005-2040.

[12]Fiese, B. H., winter, M. A., Sliwinski, M., \& Anber, R. D. (2007). Nighttime waking in children with asthma: An exploratory study of daily fluctuations in family climate. Journal of Family Psychology, 21 95-103.

[13]Forcada-Guex, M., Pierrehumbert, B., Borghini, A., Moessinger, A. \& Muller-Nix, C. (2006). Early dyadic patterns of mother-infant interactions and outcomes of prematurity at 18 months. Pediatrics, 118, e107-e114. DOI: 10.1542/peds.2005-1145.

[14]France, K. G., \& Blampied, N. M. (1999). Infant sleep disturbance: Description of a problem behavior process. Sleep Medicine Reviews, 3, 265-280

[15]Georgiades, K., Boyle, M. H., Jenkins, J. M., Sanford, M., \& Lipman, E. (2008). A multilevel analysis of whole family functioning using the McMaster family assessment device. Journal of Family Psychology, 22, 344-354.

[16] Goodlin-Jones, B. L., Burnham, M. M., Gaylor, E. E., \& Anders, T. F. (2001). Night waking, sleep-wake organization and self-soothing in the first year of life. Journal of Developmental and Behavioral Pediatrics, 22, 226-233.

[17]Hall, W., Saunders, R. A., Clauson, M., Carty, E. M., \& Janssen, P. A. (2006). Effects of an intervention aimed at reducing night waking and signaling in 6- to 12-month-old infants. Behavioral Sleep Medicine, 4 , $242-261$ 
[18]Henderson, J. M. T., France, K. G., \& Blampied, N. M. (2011). The consolidation of infants' nocturnal sleep across the first year of life. Sleep Medicine Reviews, 15, 211-220.

[19]Hiscock, H., Canterford, L., Ukoumunne, O. C., \& Wake, M. (2007) Adverse associations of sleep problems in Australian preschoolers: National population study. Pediatrics, 119, 86-93.

[20]Hiscock, H., Bayer, J.K., Hampton, A., Ukoumunne, O.C., \& Wake, M. (2008). Long-term mother and child mental health effects of a population-based infant sleep intervention: Cluster-randomized, controlled trial. Pediatrics, 122, 621-627.

[21]Holditch-Davis, D. (2010). Development of sleep and sleep problems in preterm infants. In R. E. Tremblay, M. Boivin, \& R. deV Peters (Eds.), Encyclopedia on early childhood development (pp. 1-8) [online]. Montreal, PQ: Centre of Excellence for Early Childhood Development. Available at: http://www.childencyclopedia.com/pages/PDF/Holditch-DavisANGxp3.pdf. (Accessed 31 December 2010).

[22]Huber, P. J. (1981). Robust statistics. New York: Wiley.

[23]Johnson, J. L., Ratner, P. A., Bottorff, J. L., Hall, W., \& Dahinten, S. (2000). Preventing smoking relapse in postpartum women. Nursing Research, 49, 44-52.

[24]Lam, P., Hiscock, H., \& Wake, M. (2003). Outcomes of infant sleep problems: A longitudinal study of sleep, behavior, and maternal wellbeing. Pediatrics, 111, e203-e207. DOI: 10.1542/peds.111.3.e203.

[25]Loutzenhiser, L., Ahlquist, A., \& Hoffman, J. (2011). Infant and maternal factors associated with maternal perceptions of infant sleep problems. Journal of Reproductive and Infant Psychology, 29, 460471.

[26]Magai, C., Hunziker, J., Mesias, W., \& Culver, L. C. (2000). Adult attachment styles and emotional biases. International Journal of Behavioral Development, 24, 301-309.

[27]Meltzer, L. J., \& Mindell, J. A. (2007). Relationship between child sleep disturbances and maternal sleep, mood, and parenting stress: A pilot study. Journal of Family Psychology, 21, 67-73.

[28]Mindell, J. A., Kuhn, B., Lewin, D. S., Meltzer, L. J., \& Sadeh, A. (2006). Behavioral treatment of bedtime problems and night wakings in infants and young children. Sleep, 29, 1263-1276.

[29]Morrell, J., \& Cortina-Borja, M. (2002). The developmental change in strategies parents employ to settle young children to sleep, and their relationship to infant sleeping problems, as assessed by a new questionnaire: The Parental Interactive Bedtime Behaviour Scale. Infant and Child Development, 11, 17-41.

[30]Morrell, J. M., \& Steele, H. (2003). The role of attachment security, temperament, maternal perception and care-giving behavior in persistent infant sleeping problems. Infant Mental Health Journal, 24, $447-$ 468.

[31]Muller-Nix, C., Forcada-Guex, M., Pierrehumbert, B., Jaunin, L., Borghini, A., \& Ansermet, F. (2004). Prematurity, maternal stress and mother-child interactions. Early Human Development, 79, 145-158.

[32]Radloff, L. S. (1977). The CES-D Scale: A self-report depression scale for research in the general population. Applied Psychological Measurement, 1, 385-401.

[33]Ramos, K. D., Youngclarke, D., \& Anderson, J.E. (2007). Parental perceptions of sleep problems among co-sleeping and solitary sleeping children. Infant and Child Development, 16, 417-431.

[34]Sadeh, A. (2004). A brief screening questionnaire for infant sleep problems: Validation and findings for an internet sample. Pediatrics, 113, e570- e577.

[35]Sadeh, A., Mindell, J. A., Luedtke, K., \& Wiegand, B. (2009). Sleep and sleep ecology in the first 3 years: A web-based study. Journal of Sleep Research, 18, 60-73.

[36]Scher, A. (2001). Attachment and sleep: A study of night waking in 12-month-old infants. Developmental Psychobiology, 38, 274-284.

[37]Shaha, P. E., Robbinsh, N., Coelhob, R. B., \& Poehlmannc, J. (2013). The paradox of prematurity: The behavioral vulnerability of late preterm infants and the cognitive susceptibility of very preterm infants at 36 months post-term. Infant Behavior \& Development, 36, 50-62.

[38]Sigman, M., Cohen, S. E., Beckwith, L., \& Parmelee, A. H. (1981) Social and familial influences on the development of preterm infants. Journal of Pediatric Psychology, 6, 1-13.

[39]Simola, P., Liukkonen, K., Pitkaranta, A., Pirinen, T., \& Aronen, E. T. (2012). Psychosocial and somatic outcomes of sleep problems in children: a 4-year follow-up study. Child: care, health and development, 40, 60-67.

[40]Stephens, T., \& Graham, D. F. (Eds.). (1993). Canada's health promotion survey 1990 (Tech. Rep.). Ottawa: Health and Welfare Canada.

[41]Taveras, E. M., Rifas-Shiman, S. L., Oken, E., Gunderson, E. P., \& Gillman, M. W. (2008). Short-sleep duration in infancy and risk of childhood overweight. Archives of Pediatric and Adolescent Medicine, $162,305-311$.
[42]Taylor, N., Donovan, W., \& Leavitt, L. (2008). Consistency in infant sleeping arrangements and mother-infant interaction. Infant Mental Health Journal, 29, 77-94.

[43]Teti, D. M., \& Crosby, B. (2012). Maternal Depressive Symptoms, Dysfunctional Cognitions, and Infant Night .Waking: The Role of Maternal Nighttime Behavior. Child Development, 83, 939-953

[44]Touchette, E., Petit, D., Paquet, J., Boivin, M., Japel, C., Tremblay, R. E., \& Montplaisir, J. Y. (2005). Factors associated with fragmented sleep at night across early childhood. Archives of Pediatrics \& Adolescent Medicine, 159, 242-249.

[45]Touchette, E., Cote, S. M., Petit, D., Liu, X., Boivin, M., Falissard, B., et al. (2009). Short nighttime sleep-duration and hyperactivity trajectories in early childhood. Pediatrics, 124, e985-993. DOI: 10.1542/peds.2008-2005. 